\title{
Prevalence of obesity in school children aged 11-15 years in western district of Tamil Nadu
}

\author{
Suganthi V. ${ }^{1}$, Arunthathi A. ${ }^{2}$, Nayana T. ${ }^{3}$ \\ ${ }^{1}$ Dr. Suganthi.V, Professor and HOD, Department of Pediatrics, Coimbatore Medical College Hospital, \\ Coimbatore, ${ }^{2}$ Dr. Arunthathi. A, Senior Resident, ESI Medical College, Coimbatore, ${ }^{3}$ Dr. Nayana. T, Junior \\ Resident, Coimbatore Medical College Hospital, Coimbatore, Tamil Nadu, India.
}

Corresponding Author: Dr. A. Arunthathi, Senior Resident, ESI Medical College, Coimbatore,752, Cross cut road, Andavar Complex, Gandhipuram, Coimbatore-12. E-mail id: a.arunthathi@gmail.com

\begin{abstract}
Introduction:Obesity in children and adolescents is an important public health problem in India. This study was done to estimate the prevalence of obesity in 11-15 years urban school children using Body mass index. (BMI), waist circumference (wc), waist height ratio (WHtR)and to determine the screen viewing time - arisk factor for obesity. Methods: This was a descriptive cross-sectional study. It was conducted over 12 months in the year 2014 in 11- 15 years urban school children in Coimbatore district. About 859 children were selected for this study. A proforma was used to collect the details such as age, gender, type of school, screen viewing time. Weight, height, waist circumference of these children wasmeasuredand prevalence of obesity was estimated based on the 3 indices- BMI, WC,WHtR. The data were analyzed with a statistical software package. Results: Out of the 859 children, the sample strata was 170 for each age group from 11-15 years. About 5\% were obese by BMI, $18 \%$ by WC, $14 \%$ by WHtR. The prevalence in females was $7 \%$ (BMI), $22 \%(\mathrm{WC}), 17 \%(\mathrm{WHtR})$ and in males it was $1 \%$ (BMI), 10\% (WC), 7\% (WHtR). The prevalence of obesity in private schools was 10\%. (BMI), 21\% (WC), 16\% (WHtR) and in government schools, it was 3\% (BMI), 9\% (WC), 7\% (WHtR). The prevalence in screen viewing time less than 2 hours was 3\% (BMI), 9\% (WC),12\% (WHtR) and in more than 2 hours it was 10\% (BMI), 20\% (WC), 23\% (WHtR). Conclusion: The prevalence of obesity in high school children according to BMI is 5\%., WC $18 \%$ and WHtR $14 \%$. It is more in females, children studying in private schools and in those with screen viewing time more than 2 hours.
\end{abstract}

Keywords: Childhood obesity, body mass index, waist circumference, waist height ratio.

\section{Introduction}

Childhood obesity is a serious health problem of the $21^{\text {st }}$ century as it is the precursor of adverse effects occurring in adulthood [1]. Obesity is a subclinical inflammation characterized by the secretion of cytokines that influence the formation of atherosclerotic plaques and endothelial dysfunction. This inflammatory process begins in childhood [2]. The prevalence of obesity in a population is an indicator of health burden due to non- communicable diseases in developing countries[3]. There is a great need for studying obesity in India because there is an increase in type 2 Diabetes mellitus in Indian adults[4].

Manuscript received: $6^{\text {th }}$ December 2017

Reviewed: $16^{\text {th }}$ December 2017

Author Corrected: $23^{\text {rd }}$ December 2017

Accepted for Publication: $28^{\text {th }}$ December 2017
In adolescents, central or abdominal fat increases the risk for metabolic and cardiovascular complications [5]. Indices predictive of adolescent central obesity include waist circumference (WC), waist to hip ratio (WHR), waist to height ratio (WHtR).

Only few studies could be traced in literature which estimated the prevalence of childhood obesity using all the three indices-BMI, WC, WHtR. Estimated prevalenceof obesity in school children would help in developing appropriate interventions to reduce obesity among this population. With this background we designed this cross-sectional study to estimate the prevalence of obesity using the 3 screening indices BMI,WC,WHtRamong school children11-15 years of age. 


\section{Materials and Methods}

Type of study: This was a school based descriptive cross-sectional study.

Place of study: This was carried out in urban school children in Coimbatore district, Tamil Nadu for a period of one year. Ethical clearance was obtained from Institutional ethical committee and consent was obtained from Chief Educational Officer (Coimbatore Corporation).

Inclusion criteria: Urban school children, of age 11 to 15 years were included in the study.

Exclusion criteria: Students with major dysmorphology or signs ofphysical deformity were excluded.

Sample collection: The student was considered obese 1) if he or she was more than or equal to $27^{\text {th }}$ adult equivalent of IAP BMI chart 2) WC was more than or equal to $75^{\text {th }}$ percentile of Smoothed and Weighted Age and Sex Specific Waist Circumference Percentile Values $(\mathrm{cm})$ for Indian children 3-16 years of age 3) if he or she was more than or equal to 0.5 as per the Smoothed and Weighted Age and Sex Specific Waist Height (WHt) ratio percentile values for Indian children316 years of age.

A proforma was used and details were collected which included age, gender, type of school, and screen viewing time.

Height was measured using a portablestadiometer, weightwas measured using electronic weighingscale, and WC using a non stretchable elastic tape according to WHO standards.
Sample size calculation formula $n=t^{2 *} p(1-p) / m^{2}$, wheren $=$ required sample size, $\mathrm{t}=$ confidence level of $95 \%$ (standard value of 1.96), $p=$ expected frequency of the factor under study $14.7 \%, \mathrm{~m}=$ margin of error of $2.5 \%, \mathrm{n}=1.962 * 0.147(1-0.147)$ $/ 0.0252=770$. The sample is increased by $10 \%$ to account contingencies like non-response and recording error. The sample size calculated was 850 . About $50 \%$ of samples was chosen from Government schools and $50 \%$ from private schools.

Under the above-mentioned formula, previous studies and in consultation with the statistician, the sample size was calculated to be 850 and the sample strata was calculated to be 170 for each group from 11-15 years.

Sampling method- About 859 subjects from Coimbatore district were selected for this study. We adopted a multistage stratified random sampling procedure. Schools were selected basedon the list of schools in Coimbatore, which was obtained fromthe District Education Office. Both government and private schools were included, and the ratio was $1: 1$ in accordance with distribution of schools in Coimbatore. Students who did not submit the proforma or those who were not cooperative were considered as non-respondent.

Statistical analysis- A chi square test was used to assess the difference in categorical variables between groups. A $p$ value of $<0.05$ using a twotailed test was taken as being of significance for all statistical tests. Alldata wereanalysed with a statistical software package. (SPSS, version 16.0 for windows).

\section{Results}

About 859 children were enrolled.

Table-1: Age and Gender distribution.

\begin{tabular}{|c|c|c|c|}
\hline Age & Males & Females & Total \\
\hline 11 & 68 & 106 & 174 \\
\hline 12 & 75 & 96 & 171 \\
\hline 13 & 85 & 86 & 171 \\
\hline 14 & 50 & 122 & 172 \\
\hline 15 & 61 & 110 & 171 \\
\hline Total & 339 & 520 & 859 \\
\hline
\end{tabular}

The male and female children were 339 and 520 respectively (Table-1). 
Table-2: Prevalence of obesity

\begin{tabular}{|c|c|c|c|c|c|c|}
\hline & \multicolumn{2}{|c|}{ BMI } & \multicolumn{2}{c|}{ WC } & \multicolumn{2}{c|}{ WHtR } \\
\hline \multirow{2}{*}{ Obese } & $\mathbf{n}$ & $\mathbf{\%}$ & $\mathbf{n}$ & $\mathbf{\%}$ & $\mathbf{n}$ & \% \\
\cline { 2 - 7 } & 43 & 5 & 154 & 18 & 120 & 14 \\
\hline Non -obese & 816 & 95 & 705 & 82 & 739 & 86 \\
\hline
\end{tabular}

$\mathrm{n}=$ frequency of children

According to BMI-43 Children (5\%), WC-154 Children (18\%), WHtR- 120 children (14\%) were obese. (Table2).

Table-3: Association of gender with obesity $(\mathbf{p}<0.05)$

\begin{tabular}{|c|c|c|c|c|}
\hline \multirow{2}{*}{ BMI } & \multicolumn{2}{|c|}{ Males339 } & \multicolumn{2}{c|}{ Females520 } \\
\cline { 2 - 5 } & $\mathbf{n}$ & $\mathbf{0}$ & $\mathbf{n}$ \\
\hline WC & 3 & 1 & 36 & 7 \\
\hline WHtR & 33 & 10 & 114 & 22 \\
\hline
\end{tabular}

$\mathrm{n}=$ frequency of obese children

Out of 859 children, 339 were males and 520 were females. Using all 3 indices, obesity was more common in girls than boys and it was statistically significant (table-3).

Table-4: Association of type of school withobesity $(\mathbf{p}<.05)$.

\begin{tabular}{|c|c|c|c|c|}
\hline \multirow{2}{*}{} & \multicolumn{2}{|c|}{ Private school-459 } & \multicolumn{2}{c|}{ Government school-400 } \\
\cline { 2 - 5 } & n & \% & n & \% \\
\hline BMI & 45 & 10 & 12 & 9 \\
\hline WC & 96 & 21 & 36 & 7 \\
\hline WHtR & 73 & 16 & 28 & 3 \\
\hline
\end{tabular}

$\mathrm{n}=$ frequency of obese children

Out of 859 enrolled children, 459 were from private schools and 400 from government schools. Obese children were more in private schools than in government schools and it was statistically significant(Table-4).

Table-5: Association of screen viewing time with obesity $(\mathbf{p}<0.05)$.

\begin{tabular}{|c|c|c|c|c|}
\hline \multirow{2}{*}{} & \multicolumn{2}{|c|}{ Less than 2 hours (514) } & \multicolumn{2}{c|}{ More than 2 hours (345) } \\
\cline { 2 - 5 } & $\mathrm{n}$ & $\mathbf{0}$ & $\mathrm{n}$ & 10 \\
\hline BMI & $\mathbf{1 5}$ & 3 & 69 & 20 \\
\hline WC & $\mathbf{4 6}$ & 9 & 79 & 23 \\
\hline WHtR & $\mathbf{8 8}$ & 12 & 69 & 10 \\
\hline
\end{tabular}

Among 859 children, 514 had screen viewing time less than 2 hours and 345 had screen viewing more than 2 hours. Obesity was more common in $2^{\text {nd }}$ group and it was statistically significant (Table-5).

\section{Discussion}

In our study, 859 children were taken up according to inclusion and exclusion criteria. Among the study groups, the prevalence of obesity based on BMI was
$5 \%$, WC $-18 \%$, WHtR- 4\%. Estimates of prevalence of obesity were studied by Midha $\mathrm{T}$ [6] by metaanalysis based on BMI was $3.31 \%$. Nine studies 
including 92,862 children were identified and analysed in the meta- analysis. Schroden H [7] did a study to determine the prevalence of abdominal obesitybased onWC \& WHtR in Spanish children and adolescents aged 6 to 17 years.

The prevalence of WHtR $>=0.5$ was $14.3 \%$, WC $>=$ 90 th percentile was $9.6 \%$ in adolescents. In a study by Mustaq MU [8] age and gender specific smoothed percentiles for WC, WHtR were developed for a sample of 1860 children, aged 5 to 12 years. In that study $12 \%$ children had a WC of $=>90^{\text {th }}$ centile, $16.5 \%$ children had a WHtR $=>0.5$ while $11 \%$ had both. WC provided a better estimate of visceral adipose tissue and WHtR was age independent. In the cross-sectional study by Taheri F [9] conducted on 2458Iranian students, aged 11-18 years, the prevalence of $\mathrm{WC}>90^{\text {th }}$ centile was $16.3 \%$.

A systematic review was done by de Moraes A C [10] on the prevalence of abdominal obesity in adolescents (10-19) years old, theprevalence of abdominal obesity varied from $8.7 \%$ to $33.2 \%$. This wide range is partly due to actual population disturbances and partly due to the cut offpoints used to define abdominal obesity.

Among 859 children, 339 were males and 520 were females. The prevalence of obesity based on the 3 indices (BMI,WC,WHtR) were more common in girls. This was in part due to the sedentary lifestyle. Kumar S [11] estimated the prevalence of obesity in 1496 students aged 10- 15years. The prevalence based on BMI was more common in girls $(8.82 \%)$ than boys $(4.1 \%)$. The difference was statistically significant. Bamoshmoosh M [12] estimated central obesity in a sample of 3114 Yemeni children aged 6-19 years. The prevalence based on WC and WHtR was 1.22 times more common in girls. In Yemen central obesity is more common in adult women than in men and according to this study, this difference originates at early adolescence.

Out of 859 enrolled children, 459 were private school and 400 from government schools. Obese children were more common in private schools than government schools. The prevalence was more in private schools than government schools and it was statistically significant. Children in private school were more affluent. Preetam B Mahajan[13] did a study on obesity in children between 6-12 years

\section{Original Research Article}

from government and private schools in Puducherry. Prevalence of obesity according to BMI was $1.82 \%$ in government schools and $2.48 \%$ in private schools. In a study done by Jagadesan S [14] on 18955 children aged 6-17 years across 51 schools of Chennai, the prevalence of obesity was significantly higher in private $(21.4 \%)$ compared to government schools.

Among 859 children, 514 had screen viewing time less than 2 hours and 345 had more than 2 hours. Obesity was significantly higher in second group. The American Academy of Pediatrics recommends no more than 2 hours/day of screen viewing time (watching television, videos, playing video games and using computer for purposes other than school work [15].

A meta-analysis by Zhang G [16] included 14 cross sectional studies containing 1,06,169 subjects to evaluate the association between obesity and television watching. A linear dose response relationship was found for television watching and obesity and the risk increased by $13 \%$ for each 1 hour/day increment in TV watching. There are limitations and strengths in this study.

A first limitation is the unequal number of boys and girls in the stratified age groups. Secondly the pubertal development status was not assessed.

The strengths of our study are - 1 . The novelty of comparing the 3 anthropometric indices as screening tools for obesity. 2 . The sample being obtained from both government and private schools.

\section{Conclusion}

WC and WHtR are better than BMI in detecting obesity. The prevalence of obesity is higher among girls, in children studying in private schools in Coimbatore. Screen viewing time more than 2 hours /day is associated with a higher risk of obesity. Body Mass Index is the most traditional anthropometric index used for diagnosing obesity.

This study reinforces the importance of including the WC, WHtR measurements in routine anthropometric evaluation. National programs should be aimed at periodic obesity screening of school children and sensitizing about healthy foods, outdoor activities and screen viewing hazards. 
What is already known: $\mathrm{BMI}$ is the most common anthropometric index used for diagnosing obesity.

What this study adds: WC and WHtR are better than BMI in detecting childhood obesity.

Abbreviations used: BMI - Body Mass Index, WC - Waist Circumference, WHtR - Waist Height Ratio

\section{Authors' contribution}

${ }^{1}$ Dr. Suganthi V, ${ }^{2}$ Dr. Arunthathi A, ${ }^{3}$ Dr. Nayana T

1. Concept, Design of the work, data analysis, drafting the work, editing, revising it and final approval of the article

2. Concept, Design of the work, Data acquisition, data analysis

3. Data acquisition, data analysis

Funding: Nil, Conflict of interest: None initiated, Perission from IRB: Yes

\section{References}

1. Lasserre AM, Chiolero A, Paccaud F, Bovet P. Worldwide trends in childhood obesity. Swiss Med Wkly. 2007 Mar 10;137(9-10):157-8.

2. Lyon CJ, Law RE, Hsueh W A. Mini review: adiposity, inflammation and atherogenesis. Endocrinology 2003;144:2195-2200.10.1210/en 20030285 .

3. Obesity: preventing and managing the global epidemic. Report of a WHO Consultation presented at the World Health Organisation; June 3 - 5, 1997; Geneva, Switzerland. Publication WHO/NUT/ NCD /98.1.

4. Bhardwaj S, Misra A, Khurana L et al. Childhood obesity in Asian Indians: a burgeoning cause of insulin resistance, diabetes and sub-clinical inflammation. Asia Pac J Clin Nutr 2008; 17: 172-5.

5. Bacopoulou F, Efthymiou V, Landis G, Rentoumis A, Chrousos GP. Waist circumference, waist-to-hip ratio and waist-to-height ratio reference percentiles for abdominal obesity among Greek adolescents. BMC Pediatr. 2015 May 4;15:50. doi: 10.1186/s12887-015-0366-z.
Original Research Article

6. Midha T, Nath B, Kumari R, Rao YK, Pandey U. Childhood obesity in India: a meta-analysis. Indian J Pediatr. 2012 Jul;79(7):945-8. doi: 10.1007/s12098011-0587-6. Epub 2011 Oct 15.

7. Schröder H, Ribas L, Koebnick C, Funtikova A, Gomez SF, Fíto M, Perez-Rodrigo C, Serra-Majem L. Prevalence of abdominal obesity in Spanish children and adolescents. Do we need waist circumference measurements in pediatric practice? PLoS One. 2014 Jan 27;9(1): e87549. doi: 10.1371/ journal. pone.0087549. eCollection 2014.

8. Mushtaq MU, Gull S, Abdulla HM , Shahid U, Shad MA, Akram J. Waist Circumference , waisthip ratio and waist - height ratio percentiles and central obesity among Pakistani children aged five to twelve years. BMC Pediatr. 2011 Nov 21;11:105. doi:10.1186/1471-2431-11-105.

9. Taheri F, Chahkandi T, Kazemi T, Namakin K, Zardast M, Bijari B. Prevalence of abdominal obesity in adolescents 2012, birjand, East of iran. Int J Prev Med. 2014 Sep;5(9):1198-202.

10. de Moraes AC, Fadoni RP, Ricardi LM, Souza TC, Rosaneli CF, Nakashima AT, Falcão MC. Prevalence of abdominal obesity in adolescents: a systematic review. Obes Rev. 2011 Feb;12(2):69-77. doi: 10.1111/j.1467-789X.2010.00753.x.

11. Kumar S, Mahabalaraju DK, Anuroopa MS. Prevalence of obesity and its influencing factor among affluent school children of Davangere city. Indian J Community Med 2007;32:15-7

12. Bamooshmoosh M, Massetti L, Aklan H, AlKarewany M,GoshaeHA,ModestiPA.Central obesity in Yemeni children.A population based crosssectional study.World J Cardiol.2013;5:295-304.

13. Mahajan PB, Purty AJ, Singh Z, Cherian J, Natesan M, Arepally S, Senthilvel V. Study of childhood obesity among school children aged 6 to 12 years in union territory of puducherry. Indian $\mathrm{J}$ Community Med. 2011 Jan; 36(1):45-50. doi: 10. $4103 / 0970-0218.80793$.

14. Jagadesan S, Harish R, Miranda P, Unnikrishnan R, Anjana RM, Mohan V. Prevalence of overweight and obesity among schoolchildren and adolescents in Chennai. Indian Pediatr. 2014 Jul;51(7):544-9. 


\section{Original Research Article}

15. Council on Communications and Media. From the American Academy of Pediatrics: Policy statement--Media violence. Pediatrics. 2009 Nov; 124 (5): 1495-503. doi: 10.1542/peds. 2009-2146. Epub 2009 Oct 19.
16. Gang Zhang, Lei Wu, Lingling Zhou, Weifeng $\mathrm{Lu}$, Chunting Mao. Television watching and risk of childhood obesity: a meta- analysis, European Journal of Public Health, Volume 26, Issue 1, February 2016, Pages 13-18, https://doi.org/10. 1093 / eurpub.

\section{How to cite this article?}

Suganthi V, Arunthathi A, Nayana T. Prevalence of obesity in school children aged 11-15 years in western district of Tamil Nadu. Int J Pediatr Res. 2017;4(12):727-732. doi:10.17511/ijpr.2017.i12.05. 